\title{
CLINICAL UTILITY OF CARDIAC TROPONIN I AND CARDIAC TROPONIN T MEASUREMENTS
}

\author{
Michaela Adamcová, ${ }^{1}$ Zdeněk Kokštein, ${ }^{2}$ Jaroslava Vávrová \\ Department of Physiology, Charles University, Faculty of Medicine; (Head: doc. MUDr. Z. Červinková, CSc.) \\ ${ }^{1}$ Department of Pediatrics, University Hospital, Charles University, Faculty of Medicine; \\ (Head: doc. MUDr. E. Pařízková, CSc.) \\ ${ }^{2}$ Institute for Clinical Biochemistry and Diagnosis, University Hospital, Charles University, Faculty of Medicine; \\ (Head: doc. MUDr. V. Palička, CSc.)
}

\begin{abstract}
Summary: The measurement of CK-MB remains the test of choice for confirmation or exclusion of AMI and probably will remain the test of choice for routine diagnosis in the near future. Nowadays determination of cardiac troponin $\mathrm{T}$ (cTnT) and cardiac troponin I (cTnI) as a method relatively expensive and time-consuming should be restricted to clinical settings that really require their high specificity.
\end{abstract}

Key words: Cardiac troponin T; Cardiac troponin I

\section{Introduction}

Soon after the first reports $(18,30,44)$ on serum aspartate aminotransferase (AST), lactate dehydrogenase $(\mathrm{LDH})$, and creatine kinase $(\mathrm{CK})$ activity increase in patients after acute myocardial infarction (AMI), by 1962, the World Health Organization (WHO) included the increase in cardiac enzymes into its criteria for diagnosis of definite AMI (11).

To meet clinical requirements an ideal marker of myocardial injury would (4):

1) be found in high concentration in myocardium

2) not be found in other tissues, even in trace amounts or under pathological conditions

3) be released rapidly and completely after myocardial injury

4) be released in direct proportion to the extent of myocardial injury and

5) persist in plasma for several hours to provide a convenient diagnostic time window but not so long that recurrent injury would not be identified.

Creatine kinase MB isoenzyme (CK-MB) has emerged as the biochemical marker of choice and has become the „gold standard“ of biochemical diagnosis of AMI. Recently, CK-MB activity assays have been increasingly replaced by CK-MB mass assay utilizing monoclonal-anti-CK-MB antibodies (10). Although new method for measuring CK-MB isoenzyme considerably improved the analytical sensitivity of CK-MB, there are fundamental problems with CK-MB as a myocardial marker that cannot be solved even by the most sophisticated methods. The CK-MB content of normal myocardium is small, CK-MB is not a heart-specific marker, and CK-MB is detectable in the reference populations (4).

To improve biological specifity, several research groups focused their interest on the use of myofibrillar proteins as markers of myocardial damage. Myofibrillar proteins of striated muscle are expressed as tissue-specific isoforms and consequently these antigens may be differentiated by immunologic methods. Cardiac myosin light chains, cardiac beta-type myosin heavy chains, cardiac alpha-actin, cardiac tropomyosin, as well as cardiac troponin $\mathrm{C}$ are coexpressed in slow-twich skeletal muscle fibers $(15,16,38,42)$. Only two candidates for heart-specific markers remain: cTnI and cTnT.

\section{Biochemical aspects}

Troponin is a thin-filament associated complex of the myocyte. This complex regulating calcium-dependent interaction of myosin and actin controls muscle contraction. There are three individual components in the complex, each of a single polypeptide chain. They are named after their function. Troponin $\mathrm{T}$ ( $\mathrm{TnT}$ ) binds the complex to tropomyosin, troponin $\mathrm{C}(\mathrm{TnC})$ binds calcium and then undergoes conformational changes inducing progressive change in the troponin I molecule that inhibits actin and myosin interaction in the absence of calcium (22). Troponin I and troponin T exist in three different isoforms with an unique structure, that is encoded by three different genes: one for slow-twich skeletal muscle, one for fast-twich 
skeletal muscle, and one for cardiac muscle $(37,45)$. cTnI has an extra 31 amino acid residues at the $\mathrm{N}$-terminus and its amino acid sequence shows about 40\% dissimilarity from both other isoforms (45). cTnT differs only by 6-11 amino acid residues from its skeletal muscle isoforms (37). The troponin $\mathrm{C}$ subunit is not currently explored as a cardiac marker because troponin $\mathrm{C}$ has only a fast-twich and a slow-twich/cardiac isoform (38). While the molecular mass of cTnI is approximately $24 \mathrm{kDa}$, the molecular mass of cTnT is about $37 \mathrm{kDa}$, therefore it is expected to be released rapidly from the injured myocardium $(14,47)$.

\section{Isoforms of cTnI and cTnT during development}

Cardiac troponin I is not expressed during early fetal development in humans. Though the predominant fetal cardiac troponin I isoforms is the slow skeletal TnI and complete transition to cardiac troponin takes place in humans only after birth (after the ninth postnatal month) $(12,41)$, sufficient data exist to presume that cardiac TnI remains the only troponin isoform expressed in the myocardium even during chronic disease process $(13,41)$. It is believed that cTnI is not expressed in human regenerating skeletal muscle but currently no published data exist to confirm this hypothesis.

The specificity of cardiac troponin $\mathrm{T}$ for myocardium during ontogenesis has not been fully delineated. Skeletal muscle troponin $\mathrm{T}$ and $\mathrm{CTnT}$ are coexpressed in fetal heart muscle, with the skeletal muscle form being supressed during ontogeny and reexpressed in stressed human heart (6). In contrast to cTnI, cTnT is expressed in fetal skeletal muscle and is reexpressed in adult rat skeletal muscle after injury and denervation (40).

In patients with left ventricular failure, heart biopsies also show downregulation of troponin gene toward the fetal form. The increased expression of the TnT4 isoform are associeted with a reduction of myofibrillar ATPase and may be an adaptation to the heart failure state, rather than contributing to the cause of failure (7).

\section{Analytical aspects}

Since 1989 several generations of enzyme-imunoassays specific for cardiac TnT and for cardiac TnI have been developed $(14,47)$. While the specifity of the first generation of cTnT or cTnI assay using polyclonal antibodies ranged from 97 to $100 \%(17,25)$, the new improved assays with monoclonal antibodies show no crossreactivity with skeletal troponins $(28,31)$. Although these commercially available assays (cTnT - Boehringer Mannheim, Germany and cTnI ERIA Diagnostics Pasteur, Marnes-la-Coquette, France) are fully automated, they have a turnaround time of over 90 minutes which is too long for emergency determination. That's why more rapid, qualitative, bedside immunoassay for cardiac troponin $\mathrm{T}$ using $150 \mu$ l of whole blood were developed (8). The basic principle is as follows: cTnT combi- nes with both biotinylated anti-TnT antibodies and gold-labeled anti-TnT antibodies to produce a red or purple line that is read visually within 20 minutes. The positive result is obtained in patients with $0.2 \mathrm{~g} / 1$ or more of cTnT in their blood (8).

\section{Clinical aspects}

\section{Cardiac troponin $T$}

Examination of healthy individuals showed that the normal range of cardiac troponin $\mathrm{T}$ is between 0 and 0.1 $\mu \mathrm{g} / 1$ (21,32). There are numerous studies correlating the measurement of cardiac troponin $\mathrm{T}$ against creatine kinase MB isoenzyme in patients with acute myocardial infarction (21, 32, 34, 39, 50).

Cardiac troponin T concentrations in patients with confirmed AMI showed a roughly biphasic release kinetics, with the initial peak $(9.6-22.7 \mu \mathrm{g} / \mathrm{l})$ closely paralleling that of the mass concentration of CK-MB during the first 24 $\mathrm{h}$ after the onset of symptoms. The second peak occurs on about the fourth day after admission (21,32,50). Despite a biological half-life of cTnT of $2 \mathrm{~h}$, the diagnostic time window of cTnT is unusually wide, ranging from a few hours to several weeks after the acute episode (32).

The biphasic release profile of cTnT is probably the result of intracellular compartmentation. Katus et al. (26) showed that there is an unbound cytosolic troponin $\mathrm{T}$ in ultracentrifuged homogenates of myocardial tissue of different species ranging from 0.013 to $0.036 \mathrm{mg} / \mathrm{g}$ wet weight (approximately $6 \%$ of the total troponin $\mathrm{T}$ ). The appearance of troponin $\mathrm{T}$ within the first few hours after myocardial infarction is the consequence of a rapid loss of this cytoplasmic pool superimposed on the prolonged myofibrillar degradation that results in a long plateau effect several days after the onset of pain.

The sensitivity of cTnT for the diagnosis of AMI is very high but is time-dependent. The diagnostic sensitivity of cTnT was $50 \%$ after $4 \mathrm{~h}$ and $100 \%$ from 10 to $120 \mathrm{~h}$ after the onset of pain. Sensitivity of TnT on the seventh day after admission was $84 \%$ (32). Even in patients with small myocardial necrosis, the time course of cTnT concentration contrasted more strongly with the normal range than did myoglobin, CK and CK-MB (32).

Comparison of early and late rises in troponin $\mathrm{T}$ concentration following acute myocardial infarction may provide valuable information about infarct size, reperfusion, and response to thrombolytic therapy (27). In patients with early reperfused AMI, a marked peak in troponin T serum concentrations was found at 14 hours after the onset of pain. This early troponin $\mathrm{T}$ peak was absent in patients with AMI reperfusion occurring later than 5.5 hours after the onset of pain and in patients with nonreperfused AMI. By contrast, the kinetics of troponin $\mathrm{T}$ release after the first day after AMI were unaffected by reperfusion. Troponin $\mathrm{T}$ remained elevated in all patients $14-21$ days after the onset of pain. 


\section{Cardiac troponin $T$ vs cardiac troponin I}

Mair et al. $(33,34,35)$ compared systematically cTnI with cTnT time courses in a large cohort of AMI patients and concluded that their kinetics of release into systemic circulation are very similar. There are only three important differences: 1) the larger cytosolic pool for cTnT, quoted at $6 \%$ vs the smaller $2.8 \%$ cytosolic pool for cTnI. 2) cTnT was elevated longer than cTnI and was significantly more sensitive on the 7th day after AMI. 3) the biphasic character of cTnT release, which leads to second peak about 4 days after AMI, is more pronounced than that of cTnI.

Recent reports on increased cTnT concentrations in the absence of elevated cTnI levels in patients with chronic maintenance hemodialysis for renal diseases or myopathies $(19,23,29,43)$ suggest that cTnI may be more cardiac-specific in these pacients. However, a final judgement is currently not possible, because in these studies, the old cTnT assay with some residual crossreactivity with skeletal TnT was used. Another possible explanation of this findings is that cTnT is released from poorly perfused skeletal muscle in some critically ill patients (4).

\section{Prognostic significance of cardiac troponin $T$ and cardiac troponin I}

The classic role of biochemical markers of myocyte damage in patients admitted with acute coronary syndromes has been retrospective confirmation of myocardial damage. Because cTnI and cTnT do not normally circulate in the blood and are more (for example cTnI 13 times) abundant in the myocardium than CK-MB on a weight basis, the signal-to-noise ratio associated with cardiac troponins is much more favourable for detection of minor amounts of cardiac necrosis missed by other biochemical markers. This ability is very significant because several studies $(5,9,24,36,46,48)$ have indicated that patients with acute cardiac ischemia in whom myocardial infarction was ruled out, but in whom the cTnT value exceeded a defined cutoff, were at increased risk for frank AMI or cardiac death. Although different cutoffs were used in these studies, metaanalysis by $\mathrm{Wu}$ and Lane (49) clearly demonstrated that patients with increased cTnT have fourfold increased odds for an adverse event compared with those patients for whom cTnT was negative.

Based on the available data Hamm and coworkers (24) suggested new classification of patients with unstable angina into a low-risk troponin $\mathrm{T}$ negative group and high-risk troponin $\mathrm{T}$ positive group [increased $\mathrm{cTnT}$ and $\mathrm{cTnI}$ concentrations in serum are found in about $30 \%$ of patients with unstable angina Braunwald class III - (39)].

\section{Detection of myocardial damage in neonates}

To our knowledge, the data about the diagnostic performance of troponin $\mathrm{T}$ in neonates are very seldom. Our study (1) indicates that under physiological conditions almost no myocardial troponin $\mathrm{T}$ is present in cord blood of healthy term neonates $(<0.1 \mu \mathrm{g} / \mathrm{l})$ but the concentration increases in neonates exposed in utero to infusion tocolysis with betasympathomimetics (2). The study of Genser et al. (20) as well as our results (3) demonstrated that severe birth asphyxia may also result in myocardial necrosis detectable using cardiac troponin T measurement. Although the specificity of cTnT during ontogenesis has not been fully defined the available data seem to show that cardiac troponin $\mathrm{T}$ could become a suitable criterion in laboratory diagnosis of neonatal myocardial damage but this finding deserves further investigation.

\section{Conclusions}

To sum up, the measurement of CK-MB remains the test of choice for the confirmation or exclusion of AMI and probably will remain the test of choice for routine diagnosis in the near future. Nowadays determination of troponins as a method relatively expensive and time-consuming should be restricted to certain groups of patients:

1) The patients with concomitant skeletal muscle damage in whom the high specifity of troponins is really required. There are patients for example after defibrilation or after surgical operation.

2) Further determination of troponins can be useful in case of retrospective diagnosis of AMI because the diagnostic window od troponins is wider than CK-MB.

3) The greatest utility of assays for cTnT and cTnI may be in the area of risk stratification of patients with coronary artery disease.

\section{References}

1. Adamcová M, Kokštein Z, Palička V et al. Troponin T levels in the cord blood of healthy term neonates. Physiol Res 1995;44:99-104.

2. Adamcová M, Kokštein Z, Palička V et al. Troponin T levels in neonates after acute and long-term tocolysis. Physiol Res 1995;44:8P.

3. Adamcová M, Kokštein Z, Palička V. Troponin T - marker of myocardial injury in asphyxiated neonates. J Mol Cell Cardiol 1995;27(6):A87.

4. Adams JE III, Abendschein RD, Jaffe AS. Biochemical markers of myocardial injury: Is $\mathrm{MB}$ creatine kinase the choice for the 1990s? Circulation 1993;88(2):750-63.

5. Alonsozana GL, Christenson RH. The case for cardiac troponin T: Marker for effective risk stratification of patients with acute cardiac ischemia. Clin Chem 1996;42(5):803-8.

6. Anderson PAW, Malouf NN, Oakeley AE et al. Troponin $\mathrm{T}$ isoform expression in humans: A comparison among normal and failing adult heart, fetal heart, and adult and fetal skeletal muscle. Circ Res 1991;69:122-33.

7. Anderson PAW, Malouf NN, Oakeley AE et al. Troponin $\mathrm{T}$ isoform expression in the normal and failing human left ventricle: A correlation with myofibrillar ATPase activity. Basic Res Cardiol 1992;87(suppl 1):117-27.

8. Antman EM, Grudzien Ch, Sacks DB. Evaluation of a rapid bedside assay for detection of serum cardiac troponin T. JAMA 1995;273(16):1279-82. 
9. Antman EM, Tanasjevic MJ, Thompson B. Cardiac-specific troponin I levels to predict the risk mortality in patients with acute coronary syndrome. N Engl J Med 1996; 335:1342-9.

10. Apple FS, Preese LM. Creatine kinase-MB: Detection of myocardial infarction and monitoring reperfusion. J Clin Immunoassay 1994;17:24-9.

11. Arterial hypertension and ischemic heart disease. WHO Tech Rep Ser 1962;231:18.

12. Bhavsar P, Dhoot GK, Cumming DVE et al. Developmental expression of troponin I isoforms in fetal human heart. FEBS Lett 1991;292:5-8.

13. Bodor GS, Oakley AE, Allen PD et al. Troponin I in fetal and normal and failing adult human hearts. Circulation 1992;86(Suppl I):I-842.

14. Bodor GZ. Cardiac troponin I: A highly specific biochemical marker for myocardial infarction. J Clin immunoassay 1994; 17:40-4.

15. Collinson JH, Theibert JL, Libera LD. Amino acid sequence of rabbit ventricular myosin light chain-2: Identity with slow skeletal muscle isoform. Biosci Rep 1986;6:65571.

16. Cummins P. The homology of the alpha chains of cardiac and skeletal rabbit tropomyosin. J Mol Cell Cardiol 1979; 11:109-14.

17. Cummins B, Auckland ML, Cummins P. Cardiac-specific troponin I radioimmunoassay in the diagnosis of acute myocardial infarction. Am Heart J 1987;113:1333-44.

18. Dreyfus JC, Schapira G, Resnais J et al. La creatine-kinase serique dans le diagnostic de $1 \#$ infarctus myocardique. Rev Fr Clin Biol 1960;5:386-7.

19. Escalon JC, Wong SS. False-positive cardiac troponin $\mathrm{T}$ levels in chronic hemodialysis patients (letter). Cardiology 1996;87:268-9.

20. Genser N, Ellemunter H, Mair J. Cardiac troponin $\mathrm{T}$ and $\mathrm{CKMB}$ mass concentrations in asphyxiated neonates. Clin Chem 1994;4O(6):1113.

21. Gerhardt W, Katus HA, Ravkilde J et al. S-troponin T as a marker of ischaemic myocardial injury. Clin Chem 1992; 38:1194-5.

22. Guyton AC. Textbook of medical physiology. 7th ed. Philadelphia: W B Saunders, 1986, 122-4.

23. Hafner G, Thome-Kromer B, Schaube J et al. Cardiac troponins in serum in chronic renal failure (letter). Clin Chem 1994;40:1790-1.

24. Hamm CV, Ravkilde J, Gerhardt W et al. The prognostic value of serum troponin $\mathrm{T}$ in unstable angina. $\mathrm{N}$ Engl J Med 1992;327:146-50.

25. Katus HA, Remppis A, Looser S et al. Enzyme - linked immunoassay of cardiac troponin $\mathrm{T}$ for the detection of acute myocardial infarction in patients. J Mol Cell Cardiol 1989; 21:1349-53.

26. Katus HA, Remppis A, Scheffold T et al. Intracellular compartmentation of cardiac troponin $\mathrm{T}$ and its release kinetics in patients with reperfused and nonreperfused myocardial infarction. Am J Cardiol 1991;67:1360-7.
27. Katus HA, Remppis A, Neumann FJ et al. Diagnostic efficiency of troponin T measurements in acute myocardial infarction. Circulation 1991;83:902-12.

28. Katus HA, Looser S, Hallermayer K et al. Development and in vitro characterization of a new immunoassay of cardiac troponin T. Clin Chem 1992;38(2):386-93.

29. Katus HA, Haller C, Muller-Bardorff $M$ et al. Cardiac troponin $\mathrm{T}$ in end-stage renal disease patients undergoing maintenance hemodialysis (letter). Clin Chem 1995; 41:1201-2.

30. Ladue JS, Wroblewski F, Karmen A. Serum glutamic oxaloacetic transaminase activity in human acute myocardial infarction. Science 1954;120:497-9.

31. Larue C, Defacque-Lacquement $\mathrm{H}$, Calzolari $\mathrm{C}$ et al. New monoclonal antibodies as probes for human cardiac troponin I. Epitopic analysis with synthetic peptides. Mol Immunol 1992;29:271-8.

32. Mair J, Artner - Dworzak E, Leichtner P et al. Cardiac troponin $\mathrm{T}$ in diagnosis of acute myocardial infarction. Clin Chem 1991;37:845-52.

33. Mair J, Wagner I, Puschendorf B et al. Cardiac troponin I to diagnose myocardial injury. Lancet 1993;341:838-9. 34. Mair J, Morandell D, Genser N et al. Equivalent early sensitivities of myoglobin, creatine kinase MB mass, creatine kinase isoform ratios, and cardiac troponins I and $\mathrm{T}$ for acute myocardial infarction. Clin Chem 1995;41 (9):126672.

35. Mair J, Genser N, Morandell D et al. Cardiac troponin $\mathrm{I}$ in the diagnosis of myocardial injury and infarction. Clin Chim Acta 1996;245:19-38.

36. Ohman EM, Armstrong PW, Christenson RH. Cardiac troponin $\mathrm{T}$ levels for risk stratification in acute myocardial ischemia. N Eng1 J Med 1996;335:1333-41.

37. Pearlstone J, Carpenter M, Smillie L. Amino acid sequences of rabbit cardiac troponin T. J Biol Chem 1986; 261:16795-810.

38. Pharmacek MS, Leiden JM. Structure, function and regulation of troponin C. Circulation 1991;84:991-1003.

39. Ravkilde J, Nissen H, Horder M et al. Independent prognostic value of serum creatine kinase isoenzyme MB mass, cardiac troponin $\mathrm{T}$ and myosin light chain levels in suspected myocardial infarction. J Am Coll Cardiol 1995; 25:57481 .

40. Saggin L, Gorza L, Ausoni S et al. Cardiac troponin $\mathrm{T}$ in developing, regenerating, and denervated rat skeletal muscle. Development 1990;110:547-54.

41. Sasse S, Brand NJ, Kyprianou P et al. Troponin I gene expression during human cardiac development and in endstage heart failure. Circ Res 1993;72:932-8.

42. Swynghedauw B. Adaptation of muscle contractile proteins. Phys Rev 1986;66(3):711-71.

43. Thome-Kromer B, Michel G. Human cardiac troponin I - detectability after myocardial infarction and severe skeletal muscle damage. Clin Chem 1993;39:1248.

44. Vessell ES, Bearn AG. Lactic dehydrogenase activity in blood. Proc Soc Exp Biol Med 1955;90:210-3. 
45. Wilkinson JM, Grand RJA. Comparison of amino acid sequence of troponin I from different striated muscles. Nature 1978;271:31-5.

46. Winter RJ, Koster RW, Schotveld JH. Prognostic value of troponin T, myoglobin, and CK-MB mass in patients presenting with chest pain without acute myocardial infarction. Heart 1996;75:235-9.

47. $\mathrm{Wu} \mathrm{AH}$. Cardiac troponin T: Biochemical, analytical, and clinical aspects. J Clin Immunoassay 1994;17:45-8.

48. Wu AH, Abbas SA, Green S. Prognostic value of cardiac troponin $\mathrm{T}$ in unstable angina pectoris. Am $\mathbf{J}$ Cardiol 1995; 76:970-2.

49. Wu AH, Lane PL. Metaanalysis in clinical chemistry: Validation of cardiac troponin $\mathrm{T}$ as a marker for ischemic heart diseases. Clin Chem 1995;41(8),1228-33.
50. Zabel M, Hohnloser SH, Koster W et al. Analysis of creatine kinase, CK-MB, myoglobin, and troponin T timeactivity curves for early assessment of coronary artery reperfusion after intravenous thrombolysis. Circulation 1993;87:1542-50.

Submitted October 1997.

Accepted November 1997.

MUDr. Michaela Adamcová, CSc., Department of Physiology, Charles University, Faculty of Medicine, Šimkova 870, 50001 Hradec Králové, Czech Republic. 